\title{
A mulher em cumprimento de sanções penais
}

\author{
Women under penal sanctions
}

\section{Isaura Tadioto* Sandra Regina de Abreu Pires**}

\begin{abstract}
Resumo:
Este artigo se propõe a apresentar uma caracterização das mulheres em cumprimento de medidas privativas e não privativas de liberdade no Estado de São Paulo, bem como da realidade por elas vivenciadas no cumprimento de sanções penais, buscando, na medida do possível, uma comparação com a população masculina em cumprimento das mesmas sanções. Tal exposição tem por base, no caso das privadas de liberdade, dados do Ministério da Justiça e da Secretaria de Administração Penitenciária (SAP) e, no caso das cumpridoras de medidas não privativas, pesquisa documental realizada nos Relatórios de Acompanhamento Mensais da Central de Penas e Medidas Alternativas de Presidente Prudente. Os resultados obtidos indicam que, em comparação com os homens, as mulheres enfrentam dificuldades adicionais no cumprimento de sanções penais. Indicam ainda que as desigualdades de gênero estão presentes também no universo dessas mulheres, o que se materializa nas condições de cumprimento de pena e na manutenção da responsabilização feminina pela esfera do cuidado, principalmente com as crianças.
\end{abstract}

Palavras-chave: Mulheres; Pena Privativa de Liberdade; Penas e Medidas Alternativas; Gênero; Família.

\begin{abstract}
:
The objective of this article is to characterize imprisoned and non- imprisoned women in the State of São Paulo, as well as the realities faced by them while under penal sanctions, searching, to the possible extent, for a comparison with the male population under the same sanctions. In the case of imprisoned women, such exposition is based on data from the Justice Department and SAP (Penitentiary Administration Office), and, in the case of non-imprisoned women, documental research on the Presidente Prudente Center for Penalties and Alternative Measures Monthly Follow-up Reports . Results showed that, when compared with the male population, women have to face extra difficulties when under penal sanctions. They also showed that gender inequalities are also present in the universe of these women, which are materialized in the compliance with the penal conditions and in the maintenance of the female responsibility for care taking, mainly of children.
\end{abstract}

key words: Women; Imprisonment ; Penalties and Alternative Measures; Gender; Family.

\footnotetext{
* Graduada em Serviço Social pela Faculdade de Serviço Social de Presidente Prudente. Especialista em Administração de Políticas Públicas e Mestranda em Serviço Social e Política Social pela UEL. Diretora do Centro de Penas e Medidas Alternativas da Região Oeste do Estado de São Paulo e docente da UNIESP-Campus de Presidente Prudente. E-mail: isauratadioto@uol.com.br

** Graduada em Serviço Social pela Universidade Estadual de Londrina. Mestre e Doutora em Serviço Social pela PUC-SP e docente do curso de Serviço Social da Universidade Estadual de Londrina. E-mail: spires@sercomtel.com.br
} 


\section{Introdução}

Superlotação, condições físicas inadequadas, precariedade de políticas de reinserção social e proliferação de organizações criminosas são apenas alguns dos problemas normalmente citados em relação ao sistema penitenciário, não só brasileiro. $\mathrm{Na}$ tentativa de evitar esses e outros que atingem pessoas em cumprimento de pena privativa de liberdade, bem como combater a ineficiência da prisão no tocante à finalidade de ressocialização atribuída à pena, desde meados do século XX observa-se em escala mundial um movimento significativo em torno da busca de alternativas penais que não envolvam cárcere.

No caso do Brasil, sua admissão foi possível mediante reforma processada no Código Penal em 1984. Desde então, registra-se igual movimento de ampliação legal de alternativas penais e estímulos à aplicação das mesmas. Um dos resultados disso, como informou recentemente o Departamento Penitenciário Nacional (BRASIL. MJ, 2009), é a existência, hoje, de um contingente de cumpridores que já supera em $25 \%$ o número de presos no Brasil.

Tal resultado se deve a vários fatores, sendo um deles o próprio potencial das medidas não privativas de liberdade no enfrentamento da criminalidade e dos altos índices de reincidência criminal. Todavia, há ainda no Brasil um grande contingente de pessoas vivenciando cotidianamente as condições adversas de cárcere e sendo atingido pelos malefícios dele decorrentes. Entendemos que, na comparação com o homem, para a mulher esses malefícios são ainda maiores, uma vez que se depara com dificuldades adicionais no cumprimento de penas de prisão.

A partir de nossa experiência no acompanhamento de penas e medidas alternativas, intuíamos que as mulheres enfrentavam dificuldades adicionais também no cumprimento deste tipo de sanção penal, o que nos levou a empreender um estudo sobre mulheres em cumprimento de medidas privativas e não privativas de liberdade e a realidade por elas vivenciadas no cumprimento de ambos os tipos de sanções penais.

Assim, este texto se propõe a apresentar os resultados deste estudo que tomou como referência o Estado de São Paulo. Para tal, apresenta inicialmente uma caracterização das mulheres condenadas a pena privativa de liberdade em regime fechado e de suas condições de cumprimento, tendo por fonte principal dados fornecidos 
pelo Ministério da Justiça e pela Secretaria de Administração Penitenciária do Estado de São Paulo.

Em seguida, após uma breve uma explanação sobre penas e medidas alternativas, adota-se o mesmo procedimento em relação às cumpridoras deste tipo de sanção. Constituiu-se de base para esta exposição uma pesquisa documental realizada por nós no de 2008, tendo por fonte os Relatórios de Acompanhamento Mensais dos cumpridores atendidos pela Central de Penas e Medidas Alternativas de Presidente Prudente - Estado de São Paulo. Ao final, são tecidas algumas considerações sobre a temática abordada, destacando os principais resultados obtidos.

\section{Mulheres Privadas de Liberdade}

Dados disponibilizados pelo Departamento Penitenciário Nacional (BRASIL-DEPEN, 2008) demonstram que, em dezembro de 2007, a população existente nos estabelecimentos penitenciários federais ${ }^{1}$ era de 217 pessoas. Somando a estas os presos provisórios, os em medida de segurança (de tratamento ou de internamento) e os condenados cumprindo pena em regime fechado, semi-aberto e aberto nos sistemas penitenciários estaduais, a população carcerária brasileira era, no mesmo mês, de 366.576 pessoas $^{2}$.

A partir da mesma fonte, verifica-se que o Estado de São Paulo ocupa a liderança no ranking nacional em população carcerária. Na mesma data, o sistema penitenciário paulista detinha 141.609 pessoas entre presos provisórios, condenados e em cumprimento de medida de segurança, representando $38,6 \%$ da população prisional brasileira ${ }^{3}$.

Tradicionalmente, o número de presos do sexo masculino é mais alto do que o de presos do sexo feminino e os dados do Departamento Penitenciário Nacional confirmam isso. Tomando as mesmas categorias de presos, registrava-se ao final de 2007 um total de

1 Penitenciária Federal de Catanduvas - Paraná e Penitenciária Federal de Campo Grande - Mato Grosso do Sul.

2 Acrescentando a estes os presos provisórios sob responsabilidade das Secretarias de Segurança Pública, isto é, os abrigados em Cadeias Públicas e Distritos Policiais, o total chegaria a 422.590. Informa-se que os dados numéricos apresentados a seguir excluem esse segmento de presos, haja vista a ausência de informações seguras por parte de cada unidade da federação.

${ }^{3}$ Este percentual é ainda mais significativo se observado o segundo e o terceiro lugar: Minas Gerais com 37.354 (10,2\% do total nacional) e Paraná com 28.852 (7,2\%). 
347.325 homens e de 19.043 mulheres, representando, respectivamente, $94,8 \%$ e 5,2\% da população prisional brasileira. Comparativamente com os demais, o Estado de São Paulo também liderava o ranking em termos de número de mulheres presas: 6.531, representado $34,3 \%$ do total nacional. Tomando apenas a população carcerária feminina brasileira que se encontra em cumprimento de pena privativa de liberdade em regime fechado este percentual subia para $60,7 \%$.

Também com base em dados do Departamento Penitenciário Nacional (BRASILDEPEN, 2009), São Paulo já contava em junho de 2008 com 145.096 presos, um aumento de $2,5 \%$ em relação a dezembro de 2007 . Na distribuição de condenados a pena privativa de liberdade por sexo, do total de 101.234 pessoas, $93,7 \%$ eram homens e $6,3 \%$ eram mulheres. Focando apenas o regime fechado, a proporcionalidade era de $74,6 \%$ de homens contra $5,0 \%$ de mulheres.

Informa a Secretaria da Administração Penitenciária (2009) que o sistema paulista é atualmente composto por 147 estabelecimentos penais, assim distribuídos por sexo: 03 unidades de Segurança Máxima para Regime Disciplinar Diferenciado (RDD), todas para presos do sexo masculino; 68 Penitenciárias para homens, as quais comportam 18 Alas de Progressão ${ }^{4}$ e 06 para mulheres, com apenas 01 contendo Ala de Progressão; 33 Centros de Detenção Provisória, reservados somente para presos do sexo masculino; 16 Centros de Ressocialização (CR) ${ }^{5}$ para presos e 06 para presas; 07 Centros de Progressão Penitenciária ${ }^{6}$ para homens e nenhum para mulheres e 02 Institutos Agrícolas para regime semi-aberto também exclusivamente para presos homens. Há ainda 05 Hospitais de Custódia: 03 para homens, 01 para mulheres e 01 misto, na medida em que conta com 01 ala feminina e outra masculina.

Como se percebe, o número de estabelecimentos prisionais para abrigar mulheres é muito menor do que o voltado para homens, o que se justificaria pelo maior contingente de presos do sexo masculino. Contudo, o déficit de vagas é significativo, pois,

\footnotetext{
${ }^{4}$ Ala de Progressão são unidades construídas junto às Penitenciárias e destinadas ao cumprimento de pena privativa de liberdade em regime semi-aberto.

5 Os Centros de Ressocialização foram instituídos através do Decreto estadual № 45.271/2000. Caracterizam-se por: capacidade máxima de 210 presos; estrutura física e arquitetônica diferenciada do sistema tradicional; gestão compartilhada com Organizações Não Governamentais; convivência de diferentes regimes numa mesma unidade; prioridade no atendimento de presos da região jurisdicional e destinação para presos que apresentem, após seleção, potencial para a mudança.
} 
conforme o Departamento Penitenciário Nacional (BRASIL-DEPEN, 2009), em junho de 2008 o índice era de 20,9\%: uma superlotação de 1.055 mulheres, sendo 915 no sistema fechado e 140 no semi-aberto.

A partir da mesma fonte constata-se que a maioria das mulheres privadas de liberdade no Estado de São Paulo, como também os homens, se encontra na faixa etária de 18 a 29 anos. Na população feminina, o percentual nesta faixa é de $52,8 \%$, seguida da de 30 a 45 anos (39,9\%), da de 46 a 60 anos (6,8\%) e da de acima de 60 anos (0,5\%).

Quanto à escolaridade, a distribuição é a seguinte: 2,9\% de analfabetas; $13,8 \%$ de alfabetizadas; $37,5 \%$ com ensino fundamental incompleto; $17,2 \%$ com ensino fundamental completo; $12,2 \%$ com ensino médio incompleto; $14 \%$ com ensino médio incompleto; $1,5 \%$ com ensino superior incompleto; $1 \%$ com ensino superior incompleto ${ }^{7}$. Desta forma, embora haja um percentual significativo de mulheres com ensino médio completo ou incompleto $(26,1 \%)$, prevalece como majoritário o segmento com ensino fundamental completo ou incompleto $(54,7 \%)$. Ademais, somando-se as com ensino fundamental incompleto e as analfabetas ou apenas alfabetizadas, tem-se um percentual de $54,4 \%$, permitindo a caracterização da população prisional feminina como de baixa escolaridade.

No ano de 2002, a Secretaria de Administração Penitenciária de São Paulo realizou um Censo Penitenciário, o qual permite um maior detalhamento das características da população carcerária feminina e masculina existente no estado naquele ano. Partindo deste Censo (SÃO PAULO-SAP, 2003), observa-se que a maioria das mulheres era solteira (54\%), seguida das casadas/amasiadas (27\%), das separadas, divorciadas ou desquitadas (11\%) e das viúvas (8\%).

Pelo mesmo Censo, apenas $18 \%$ das encarceradas não possuíam filhos. Entre as que os possuíam, $44 \%$ tinha entre 01 e 02 filhos; 18\% tinham $03 ; 10 \%$ tinham 04 ; e também 10\% tinham 05 ou mais filhos. A Lei de Execução Penal resguarda direitos à convivência das mulheres condenadas com seus filhos menores. Um deles está previsto no inciso III do artigo 117, garantindo à mulher "condenada com filho menor ou

\footnotetext{
${ }^{6}$ Centro de Progressão Penitenciária são unidades que abrigam presos em regime semi-aberto e que apresentem bom comportamento

${ }^{7}$ Os restantes $0,1 \%$ se referem ao percentual em relação ao qual o DEPEN nacional não tem informações por não terem sido disponibilizadas pelo Estado de São Paulo.
} 
deficiente físico ou mental" a possibilidade de cumprimento da pena em regime aberto e em residência particular.

Estando recolhida em estabelecimento penal, este deve oferecer condições físicas diferenciadas em comparação com os masculinos. Dentre elas, a obrigação de ser "dotado de berçário, onde as condenadas possam amamentar seus filhos" ( $₹ 2$ do artigo 83) e a possibilidade de conter "seção para gestante e parturiente e de creche com a finalidade de assistir ao menor desamparado cuja responsável esteja presa" (artigo 89). Portanto, a lei não faz referência específica ao tempo de permanência dos filhos junto à mãe, mas garante, a princípio, a convivência materna durante o período de aleitamento materno e durante a faixa etária prevista para Creche. Segundo a Lei de Diretrizes e Bases da Educação Nacional, em seu artigo 30, esta faixa etária é de até 03 anos de idade.

Apesar desta determinação legal, nem todas as unidades femininas oferecem essas condições. No Estado de São Paulo, como informa Daniel (2008), as 06 existentes no ano de 2008 não foram construídas originalmente para abrigar mulheres e sim adaptadas para recebê-las. Os inconvenientes disso seriam minimizados com a entrega, prevista para 2009 , de 08 penitenciárias femininas ${ }^{8}$, gerando cerca de 6.000 novas vagas. Isso permitiria o esvaziamento das carceragens femininas sob a responsabilidade da Secretaria de Segurança Pública e minimizaria a superlotação das de responsabilidade da Secretaria de Administração Penitenciária. Além disso, destaca Daniel (2008, p. 5), estas unidades teriam sido projetadas para atender as necessidades das mulheres, contendo, pois,

creche, biblioteca, pavilhão de trabalho, além de setor destinado à visita íntima [...] Outro detalhe referente aos novos estabelecimentos prisionais distribuídos pelo Estado é o fato deles abrigarem mulheres na região em que cometeram seus crimes. Tal medida aproxima a reeducanda de sua família, o que é extremamente positivo para o processo de ressocialização.

A partir destas informações, subentende-se que as unidades hoje existentes no estado não garantem, ou não garantem satisfatoriamente, a permanência dos filhos menores com a mãe, estando os mesmos sob responsabilidade do pai ou do companheiro. Porém, considerando que $73 \%$ das mulheres não têm companheiro, a

\footnotetext{
${ }^{8}$ As quais estariam sendo construídas nos municípios de: Bom Jesus dos Perdões, Guariba, Mogi Guaçu, São Vicente, Pirajuí, Tremembé, Votorantim e Tupi Paulista.
} 
prisão delas tende a desencadear dificuldades relativas ao cuidado com os filhos, algo que não se verifica com freqüência no tocante à população carcerária masculina. Isto é, quando o preso é o pai, é comum que os cuidados fiquem ao encargo da companheira, genitora ou não da criança. Quando a presa é a mãe, a tendência é que fiquem com a família materna ou, na ausência desta, se processe o encaminhamento dos filhos para alguma instituição, tornando a separação entre mãe e filhos ainda mais traumática.

No concernente às atividades laborais no interior das unidades prisionais, o artigo 41 da Lei de Execução Penal fixa que as mesmas se constituem em um direito do preso, o qual deve, por elas, receber uma remuneração. Segundo o Censo Penitenciário (SÃO PAULO-SAP, 2008), para $60 \%$ da população carcerária feminina essa remuneração estava na faixa de $\mathrm{R} \$ 121,00$ a $\mathrm{R} \$ 200,00$. As $40 \%$ restantes estavam assim distribuídas: $22 \%$ na faixa de $\mathrm{R} \$ 81,00$ a $\mathrm{R} \$ 120,00 ; 10 \%$ na faixa de $\mathrm{R} \$ 21,00$ a $\mathrm{R} \$ 80,00 ; 6 \%$ com remuneração acima de $\mathrm{R}$ 201,00; $1 \%$ com remuneração abaixo de $\mathrm{R} \$ 20,00$ e $1 \%$ sem nenhuma remuneração.

O destino desses proventos era, na mesma proporção de $58 \%{ }^{9}$, para si mesmas e para a família. Uma minoria, 5\%, enviava para outras pessoas. Este dado nos permite inferir que, mesmo estando presas, a preocupação das mulheres recai sobre a família ou sobre aqueles que provavelmente estão cuidando de seus filhos. Isto se coaduna com a afirmativa de Saraceno $(1995$, p.217) de que "as mulheres investem muito mais na família que os homens, em termos de tempo, energia psíquica, atenção - e espera-se que o faça". A elas é atribuída socialmente a responsabilidade pelos cuidados familiares, mesmo em sua ausência física.

Outro dado permitido pelo Censo Penitenciário (SÃO PAULO-SAP, 2008) é que 36\% das mulheres aprisionadas não recebiam visita. Entre as que recebiam, 19\% eram visitadas todas as semanas; $19 \%$ duas vezes ao mês; $14 \%$ uma vez por mês, $11 \%$ menos que duas vezes por mês e $1 \%$ três vezes por mês. Vê-se, pois, que o número de mulheres que não recebiam visita era significativamente alto e que, considerando a quantidade de visitas durante o mês, em outros $25 \%$ a periodicidade era baixa, não permitindo à mulher

\footnotetext{
${ }^{9}$ Infere-se que o fato da somatória atingir mais que $100 \%$ é produto da metodologia adotada na pesquisa ou do estilo da pergunta, isto é, pressupomos que parte das mulheres deve ter respondido que uma parcela da remuneração vai para a família e outra fica com elas.
} 
o apoio familiar que é considerado fator muito importante no processo de cumprimento de pena.

Concentrando-nos no percentual de $64 \%$ que eram visitadas, verifica-se que os maiores visitadores eram os filhos. Considerando que a metodologia do Censo permitia para este quesito mais de uma resposta, os filhos eram responsáveis por $48 \%$ das visitas, vindo em seguida as mães (47\%), os irmãos (45\%), os companheiros (18\%), os pais (14\%), os amigos (11\%) e outros parentes como tios, avós e netos (18\%). Deduz-se, portanto, que mesmo na privação de liberdade, a maternidade é o vínculo mais forte estabelecido com a família, isso demonstrado tanto pelas visitas dos filhos quanto das genitoras que, no conjunto, se faziam presentes em $95 \%$ das visitas recebidas.

Chama a atenção nestas informações o baixo número de visitas por parte dos companheiros, o que poderia ser explicado pelo fato de que apenas $27 \%$ das presas eram casadas ou viviam em união estável. Todavia, esta explicação não é suficiente se compararmos a população prisional feminina com a masculina. Enquanto $65 \%$ das visitas masculinas eram de companheiras, as quais até dormem nas filas para visitá-los, para as mulheres o percentual era de somente $18 \%$.

Assim, pode-se dizer que o índice de abandono por parte do parceiro é maior no caso das mulheres do que dos homens, o que não se processa em relação à família. Comparando quem visitava o preso e a presa, a presença da mãe e do pai era mais ou menos equivalente ( $51 \%$ e $15 \%$ para os homens e $47 \%$ e $14 \%$ para as mulheres), mas a proporção de filhos era mais que o dobro (23\% para os homens contra $48 \%$ para as mulheres), bem como de outros parentes ( $7 \%$ contra $18 \%$ ).

Este aspecto é confirmado por Sucupira (2006) ao discutir dados revelados por uma pesquisa realizada pela Pastoral Carcerária e pelo Instituto Terra, Trabalho e Cidadania (ITTC) em maio de 2006 sobre a situação das mulheres encarceradas em São Paulo. Segundo as mulheres presas entrevistadas no estudo, a "perda do contato com o marido ou o parceiro se deve a uma série de restrições à visita de homens, que dificultam a manutenção da intimidade e dos laços emocionais" (SUCUPIRA, 2006), sendo uma delas a relativa às visitas íntimas.

A autora compartilha deste posicionamento, uma vez que, enquanto os homens presos no Estado de São Paulo têm direito a este tipo de visita há mais de 20 anos, elas 
passaram a ser admitidas para as mulheres apenas a partir de 2002 sob pressão de grupos de defesa de direitos humanos. Não obstante, elas se revestiam de maiores restrições para as mulheres, pois continuavam sendo proibidas nas cadeias públicas onde se encontravam aproximadamente $53 \%$ das encarceradas. Além disso, nas unidades penais que admitiam visitas íntimas,

\begin{abstract}
Ao contrário do que acontecia aos presos homens, os parceiros das mulheres passavam por um estreito processo de qualificação antes de poderem participar da visita. As permitidas só eram disponíveis às mulheres com parceiros "estáveis", o que o casal era obrigado a provar com certidão de nascimento do filho, certidão de casamento ou declaração de união estável, informa o estudo. Segundo os funcionários das penitenciárias, devido aos riscos de gravidez ou de doenças sexualmente transmissíveis, era do interesse da saúde das mulheres que fossem estabelecidas condições diferentes nas penitenciárias femininas, numa clara atitude discriminatória (SUCUPIRA, 2006).
\end{abstract}

Concordando com a autora, entendemos que além de discriminatória essa postura dos estabelecimentos penais, através de seus funcionários, denota o exercício de um poder que impele a pena para além das restrições que ela própria impõe. Ou seja, as mulheres já estão presas, perdendo, deste modo, alguns direitos, mas a isso é acrescida a proibição de alguns outros que não estão (e não deveriam estar) abrangidos pela sanção penal. É deste modo que, em nome da instituição que representam, os funcionários exercem um poder de decisão sobre um assunto que caberia às mulheres. Eles assumem uma postura de dominação, respondendo em nome das mulheres, a quem caberia a responsabilidade pelas suas opções. Mesmo privadas de liberdade, elas tem a capacidade de discernir e de decidir, por si, o que é melhor para suas vidas.

Quanto à relação das mulheres presas no Estado de São Paulo com o mundo do crime, o mencionado Censo nos dá ciência de que apenas 9\% delas haviam tido passagem anterior pela FEBEM ou por outra instituição destinada ao atendimento de adolescentes em conflito com a lei. Este dado pode indicar que a situação de vulnerabilidade feminina é maior após a maioridade, indicação esta reforçada pelo fato de que, em conformidade com Departamento Penitenciário Nacional (BRASIL-DEPEN, 2009), 74,4\% das mulheres presas no Estado de São Paulo em junho de 2008 era réu primário com uma condenação $(48,9 \%)$ ou mais de uma condenação (27,6\%). Tinha-se, então, um índice de $23,6 \%$ de reincidentes, percentual bastante inferior ao dos homens que era de $40,8 \%$. 
Esta disparidade pode permitir a conclusão de que o grau de periculosidade da população prisional masculina do Estado de São Paulo é maior do que o da feminina. Ainda que não tenhamos elementos empíricos para tal afirmação, uma análise dos dados concernentes aos tipos de crimes mais comuns e ao tempo de pena imputado sugere a confirmação disso. Com base na mesma fonte, verificava-se que a maioria das mulheres, $50,2 \%$, foi sentenciada com penas de até 04 anos, enquanto este percentual para os homens era de $19,2 \%$. Isto é, o percentual de mulheres nesta faixa menor de tempo de pena era quase o triplo do dos homens, proporção que se invertia quando se tratava de penas maiores. Excetuando a faixa de 04 a 08 anos na qual não havia grande disparidade - 29,8\% para mulheres contra $30,6 \%$ para homens - nas demais a proporção era sempre superior atingindo o dobro ou mais ${ }^{10}$.

Fazendo referência específica às mulheres, é importante destacar que esse tempo de pena de até 04 anos, na qual se concentravam mais da metade das mulheres, é normalmente imputado a crimes que não são considerados de alto poder ofensivo ou que tenham sido cometidos sem altos graus de violência e ameaça. De fato, com base na mesma fonte ${ }^{11}$, verificava-se que $1 / 4$ das mulheres haviam sido condenadas pela prática de crimes como roubo $(14,7 \%)$, furto $(5,4 \%)$, extorsão $(2,6 \%)$, falsificação de documentos $(1,1 \%)$, receptação $(0,7 \%)$ e atentado violento ao pudor $(0,3 \%)$. A maior proporção era, de longe, o tráfico de drogas, cuja prática gerou a condenação e encarceramento de 50,8\% das mulheres. Se somarmos o tráfico internacional de drogas, este percentual subia para $53,2 \%$.

Esta maior incidência do tráfico de drogas não é específica das mulheres, haja vista o crescimento exponencial que o mesmo tem apresentado em todo o mundo. Porém, no caso delas isso pode estar articulado, ou ser dependente, de outros aspectos. Como exposto, a maioria era mãe, em média de dois filhos, e não possuía companheiro, o que as colocava majoritariamente na condição de arrimos de família. Por esta condição, é possível inferir que as mesmas se tornam mais vulneráveis aos traficantes que tendem a

\footnotetext{
${ }^{10}$ Dois exemplos são as faixas de 08 a 15 anos de pena e a de 15 a 20 anos. Nestas faixas os percentuais eram, respectivamente, $11 \%$ e $3,9 \%$ de mulheres contra $24,2 \%$ e $11,2 \%$ de homens.

${ }^{11}$ Esclarece-se que é comum a condenação pela prática de mais de um crime, aspecto que não foi considerado no documento disponibilizado pelo Departamento Penitenciário Nacional (BRASIL-DEPEN, 2008) e que nos serve de fonte para estes comentários.
} 
recrutar para o comércio ilegal de drogas adolescentes e mulheres chefes de família em dificuldades econômicas.

Esta possibilidade torna-se mais reforçada se lembrarmos que a maioria não apresentava trajetória de envolvimento anterior com o mundo do crime, mesmo na condição de adolescente infrator. Ademais, como demonstram os dados acima expostos em relação ao delito, excetuando o tráfico de drogas, o maior percentual dizia respeito a crimes contra o patrimônio, ou seja, atos ilícitos que envolvem retorno financeiro imediato.

O conjunto destas características pode indicar que uma das motivações para a inserção das mulheres no mundo do crime pode ser a situação econômica vivenciada, o que as levaria a buscar, através do ato ilícito, suprir necessidades demandadas pelo grupo familiar, em particular pelos filhos. No entanto, o encarceramento, como conseqüência de tal prática, acaba agravando ainda mais as condições vividas: além de serem privadas de sua liberdade, são separadas dos filhos (causando sofrimento para ambas as partes) e vêem aumentadas suas dificuldades em suprir suas necessidades individuais e familiares. Este aspecto, somado às condições de cárcere, faz com que a realidade da mulher encarcerada apresente um quadro extremamente problemático, talvez em grau até maior que o dos homens.

Como elemento complicador, não se visualiza políticas públicas capazes de atender as necessidades específicas das mulheres encarceradas, tornando este quadro de difícil reversão. Sobre isso, Heidi Cerneka, Coordenadora Nacional da Pastoral Carcerária Feminina no Brasil, afirma que, "infelizmente não há políticas públicas sobre a situação da mulher presa. Elas não cavam túneis, raramente fazem rebelião, são menos violentas e não saem nos jornais. São Invisíveis e esquecidas pelo Estado" (CERNEKA, 2004).

Em outras palavras, mesmo na condição de presa a mulher é mais penalizada, ainda, ou justamente porque, é minoria no sistema prisional e, na comparação com os presos do sexo masculino, se comporta mais adequadamente frente às normas estabelecidas. Também segundo Cerneka (2004), "seria muito saudável se houvesse penas alternativas que exigem que a infratora repare os danos à sociedade reintegrandose, assim, a ela ao invés de separar a mulher da sua família". Concordamos totalmente 
com esta posição, na medida em que, como veremos a seguir, as penas e medidas alternativas trazem inúmeras vantagens em face das privativas de liberdade.

\section{Alternativas ao Cárcere}

No Brasil, as mulheres agentes de crime, assim como os homens, não precisam necessariamente ser condenadas a pena de prisão e viver a realidade antes descrita. No sistema penal brasileiro estão previstas alternativas penais que podem, sob determinadas condições e circunstâncias, substituir a privativa de liberdade, sendo, por isso, denominadas de penas ou medidas alternativas.

Conforme Sznick (2000 apud BRASIL, MJ, 2002, p.13), a "pena alternativa é uma medida punitiva de caráter educativo e socialmente útil, imposta ao autor da infração penal" e destinada a infratores considerados de baixo potencial ofensivo. Em nosso ordenamento jurídico, elas equivalem à de multa e às restritivas de direito, previstas desde a reforma do Código Penal processada em 1984. Atualmente, após a promulgação da Lei 9.714/98, que processou novas alterações neste Código, as mesmas estão regulamentadas pelos artigos 43 a 52 .

De acordo com o artigo 49 do Código Penal brasileiro, a pena de multa se configura em "pagamento ao fundo penitenciário da quantia fixada na sentença e calculada em dias multa". As penas restritivas de direito, por outro lado, como estabelece o artigo 43, compreendem cinco modalidades: prestação pecuniária, perda de bens e valores, prestação de serviços à comunidade ou a entidades públicas, interdição temporária de direitos $^{12}$ e limitação de final de semana.

Quanto às medidas alternativas, figuram no ordenamento jurídico brasileiro desde a aprovação da Lei 9.099 em 1995 (Lei dos Juizados Especiais Criminais) que introduziu a suspensão condicional do processo e a transação penal. Como esclarece documento divulgado pelo Ministério Público do Paraná (PARANÁ, MP, 2008), esses dois institutos são possíveis a partir de proposta efetivada pelo Ministério Público a acusados com previsão de pena mínima igual ou inferior a um ano por ocasião do oferecimento da

\footnotetext{
${ }^{12}$ Em meio a estas, o Código Penal, em seu artigo 47, inclui: proibição do exercício de cargo, função ou atividade pública, bem como de mandato eletivo; proibição de exercício de profissão, atividade ou ofício que dependam de habilitação especial, de licença ou autorização do poder público; suspensão de autorização ou habilitação para dirigir veículo; proibição de freqüentar determinados lugares.
} 
denúncia. Aceito o acordo feito frente ao juiz e a vitima, o acusado não chega a ser julgado ou condenado. Em decorrência,

cumprem medida alternativa as pessoas que estão sendo processadas judicialmente por um delito de médio a pequeno potencial ofensivo. Por serem réus primários e não oferecerem risco à sociedade, o Ministério Público apresenta-lhes uma proposta que, se aceita, tornará suspenso o processo pelo período de 02 anos a 04 anos (dependendo do caso concreto). Nesta proposta, além do período de prova ( 2 a 4 anos), estarão presentes outras condições (determinadas no termo de audiência) que deverão ser cumpridas [...] (PARANÁ, MP, 2008, p. 2).

Entre essas condições estão a prestação de serviços à comunidade, a doação de gêneros diversos (alimentos, medicamentos, etc.), o retorno aos estudos, a adesão a tratamento para desintoxicação e o encaminhamento para cursos profissionalizantes.

A diferença entre pena e medida alternativa não está, pois, na gravidade do delito cometido, já que em ambos os casos o ato gerador da acusação é de pequeno ou médio poder ofensivo. A diferença está no fato de que os(as) beneficiados(as) com medida alternativa não chegam a ser julgados(as) e condenados(as), enquanto os(as) contemplados(as) com pena alternativa responderam processo, foram julgados(as) e condenados(as) por um Juiz com sentença definitiva, seja ela multa ou alguma das modalidades antes citadas.

Por esta diferença, no caso da prestação de serviços à comunidade o período de cumprimento tende a ser menor para os sancionados com medida alternativa, bem como a inflexibilidade em relação às condições de cumprimento determinadas judicialmente. No entanto, os requisitos necessários para que a pessoa tenha direito a uma pena ou medida alternativa não são díspares. Segundo consta do Manual de Monitoramento das Penas e Medidas Alternativas (BRASIL, MJ, 2002, p.14), esses requisitos são:

\footnotetext{
- Pena privativa de liberdade não superior a quatro anos;

- Crime sem violência ou grave ameaça à pessoa;

- Qualquer que seja a pena se o crime for culposo, em razão de imprudência, negligência ou imperícia;

- Não reincidência em crime doloso, que se refere àquele com intenção de se atingir o resultado ou assumir o risco de produzir o delito;

- Verificação da culpabilidade, antecedentes, conduta social e personalidade do condenado, bem como motivos e circunstâncias que indiquem a substituição.
} 
A partir disso, apesar das diferenças existentes, esses dois institutos legais concentram igualmente a capacidade de evitar a imposição de cárcere. Neste sentido, ainda que tenham um caráter punitivo inerente a qualquer sanção penal, encerram vantagens no cotejamento com as penas de prisão como, por exemplo, a não produção de afastamento da pessoa condenada de seus familiares e da sociedade e, portanto, a segregação social, bem como o impedimento de que a mesma seja atingida, individual e socialmente, pelos malefícios decorrentes das condições adversas do cárcere. Também processam (ou buscam processar) uma mudança na imagem das penas. Através delas, a punição deixa de ser sinônimo de cadeia, pois os sancionados, por não estarem em regime fechado, as cumprem junto à comunidade, permitindo que ambos se beneficiem e se integrem.

Por estas vantagens e observando o princípio da dignidade humana, a Organização das Nações Unidas (ONU) aprovou uma Resolução que se tornou referência para todos os países membros, incluindo o Brasil, na adoção e aplicação de alternativas penais. Trata-se da Resolução no. 45/110 intitulada "Regras Mínimas para a Elaboração de Medidas não Privativas de Liberdade" aprovada em 14/12/1990, durante seu 8 o Congresso realizado em Tóquio. Por ela, também conhecida como "Regras de Tóquio", a ONU defende a aplicação de sanções alternativas à prisão, advogando pela reserva desta somente para atos de maior poder ofensivo ou para agentes que apresentem maior grau de periculosidade.

No Brasil, embora a reforma do Código Penal de 1984 já tivesse introduzido em nossa legislação as penas alternativas, foi a partir desta Resolução que a aplicação das mesmas começou a avançar em termos numéricos e quanto à demonstração da capacidade de se instituírem enquanto meios mais eficazes de melhoria na prevenção da criminalidade e no tratamento dos delinqüentes.

Não obstante e ainda que sejam relativamente novas em comparação com a privação de liberdade, já há pesquisas apontando para a necessidade de revisão na legislação, de forma a poder atingir um número ainda maior de pessoas. Afirma Kátia Brasil (2008) que uma pesquisa realizada pelo Ministério da Justiça, Programa das Nações Unidas para o Desenvolvimento (PNUD) e Fundação Getúlio Vargas "aponta que 25\% da população carcerária que cumpre pena no Brasil - aproximadamente 59 mil pessoas - 
poderia deixar os presídios se a Justiça flexibilizasse critérios para aplicação de penas alternativas". Complementa dizendo que, caso a flexibilização incidisse sobre o critério da reincidência e da ausência de grave ameaça, o percentual subiria para 90\%.

Este argumento encontra base no concernente à população prisional feminina do Estado de São Paulo. Como mencionado, perto de 50\% havia sido sentenciada com penas de até 04 anos, o que, por si só, colocaria cerca de 2.600 mulheres em condição de pleitear a substituição de sua pena privativa de liberdade por pena alternativa. Por outro lado, como $1 / 4$ da população carcerária feminina paulista havia sido condenada por crimes como furtos, roubo, falsificação de documentos e outros, com a citada flexibilização o número de mulheres nesta condição poderia ser bastante ampliado.

Mesmo sem essa flexibilização é notório o avanço que a aplicação de alternativas penais obteve nos últimos anos, contribuindo para isso, em boa medida, o aumento de Centrais de Penas e Medidas Alternativas ou órgãos similares em várias estados brasileiros. Dentre eles está o Estado de São Paulo que, seguindo os parâmetros postos pela legislação vigente, conta atualmente com 30 Centrais, estando previstas a inauguração de mais 10 ainda neste ano de 2009.

Segundo dados internos, catalogados pela Coordenadoria de Reintegração Social e Cidadania da Secretaria da Administração Penitenciária, estas Centrais atendiam, em fevereiro de 2009, um total aproximado de 11.200 cumpridores de pena ou medida alternativa, possibilitando a elas as vantagens inerentes a deste tipo de sanção penal. Distribuídos por sexo, registra-se $86 \%$ de homens e $14 \%$ de mulheres, o que dá à população feminina a posição de minoria também no cumprimento de penas e medidas alternativas.

Para estas cerca de 1.600 mulheres, a realidade do cumprimento de pena é bastante diferenciada daquela descrita no tocante às privadas de liberdade. Desse modo, como procedemos no item anterior, no próximo procuramos apresentar uma caracterização delas e da realidade por elas vivenciada. A referência é a Central de Penas e Medidas Alternativas de Presidente Prudente, a partir de uma pesquisa por nós efetuada junto aos Relatórios de Acompanhamento Mensais dos cumpridores atendidos por esta Central desde sua implantação, ou seja, de 07 de julho de 2006 até a data base de 31 de dezembro de 2008. 


\section{Mulheres em Cumprimento de Pena ou Medida Alternativa}

Pela pesquisa supracitada, constatou-se na Central de Penas e Medidas Alternativas de Presidente Prudente igual disparidade em termos de distribuição por sexo. Do total de 490 cadastrados, 409 eram do sexo masculino e somente 81 do sexo feminino, equivalendo, respectivamente, a $83,5 \%$ e $16,5 \%$. Este percentual de mulheres é muito maior do que o obtido no tocante à população prisional $(93,7 \%$ contra $6,3 \%)$, mas ainda as coloca em igual condição de minoria dentre as pessoas que cumprem uma pena ou medida alternativa.

Tomando apenas o universo feminino, o percentual de solteiras é igual ao de casadas - 31\% - registrando-se também 19\% vivendo em união estável, 18\% divorciadas ou separadas judicialmente e $1 \%$ de viúvas. Assim, há uma proporção igualitária entre as que possuem companheiro e as que não possuem: $50 \%$, distanciando-se bastante da verificada dentre as apenadas com prisão que é de $27 \%$ com companheiro e $73 \%$ sem companheiro.

Quanto à faixa etária, a maior parte se situa na de 21 a 30 anos: 37\%. A ela seguem a faixa etária de 31 a 40 anos (29\%), a de 41 a 50 anos (23\%), a de 51 a 60 anos (5\%) e a de acima de 60 anos (6\%). A escolaridade das mulheres está concentrada em índice de $34 \%$ no ensino fundamental incompleto. A segunda maior incidência é de $21 \%$ no ensino médio completo, seguido de $18 \%$ no ensino fundamental completo, $11 \%$ no ensino superior completo, $10 \%$ no ensino médio incompleto, $5 \%$ no ensino superior incompleto e $2 \%$ na condição de analfabetas.

Ainda que com uma distribuição mais equitativa, percebe-se que a idade e a escolaridade destas mulheres são semelhantes às encontradas dentre as privadas de liberdade. A discrepância significativa se assenta no ensino superior: enquanto nas aprisionadas há 2,5\% com ensino superior completo ou incompleto, dentre as cumpridoras de penas e medidas alternativas este percentual é de $16 \%$.

Apesar dessa discrepância, de modo geral os dados revelam uma população jovem de até 30 anos e que possui escolaridade de até o ensino fundamental incompleto. Isso nos leva a reafirmar a necessidade de políticas públicas específicas para detentoras deste 
perfil, funcionando como prevenção à criminalidade tanto por parte das condenadas com penas de prisão como das sancionadas com penas e medidas alternativas.

Essa necessidade se mostra reforçada se for considerada a situação sócioeconômica. Pela pesquisa realizada, a renda familiar mensal se concentra na faixa de 01 a 02 salários mínimos (30\%), seguida de $28 \%$ na de 01 salário mínimo. As que declaram não ter renda e ganharem entre dois e três salários mínimos somam o mesmo percentual: 18\%. Também foi detectado um mesmo percentual, de $2 \%$, dentre aquelas que têm renda familiar entre 03 e 05 salários mínimos, entre 05 e 10 dez salários mínimos e acima de 10 salários mínimos.

Como se percebe, a maioria absoluta - 58\% - tem renda familiar mensal inferior a 03 salários mínimos, indicando baixo nível sócio-econômico. Se acrescermos as que declaram não ter renda, este percentual sobe para $60 \%$, corroborando nossa observação empírica de que estas mulheres, tal como as privadas de liberdade, estão em situação de vulnerabilidade social, com pouco acesso a bens e serviços necessários a um nível adequado de qualidade de vida.

Em relação ao vínculo empregatício, 37\% são autônomas, 32\% se encontram desempregadas, $18 \%$ então trabalhando em empresa privada, $8 \%$ são servidoras públicas e 5\% são aposentadas. Assim, a maioria possui renda mensal própria, não dependendo exclusivamente do parceiro para sua sobrevivência. No entanto, isso não chega a significar um diferencial financeiro positivo, haja vista que, como apontado, uma parcela significativa está na condição de arrimo de família e a renda familiar está majoritariamente em valor igual ou inferior a 03 salários mínimos.

No tocante ao histórico criminal, a maioria é ré primária, uma vez que $86 \%$ não cumpriram nenhum outro tipo de condenação anterior. Os $14 \%$ restantes se subdividem em $8 \%$ que já foi alvo de outra pena ou medida alternativa e $6 \%$ de pena privativa de liberdade em regime fechado. Este alto percentual de primários não é fator de estranhamento, já que, como referido, a não reincidência é critério legal para concessão de alternativas penais. Outro critério é a prática de crime sem violência ou grave ameaça à vítima que qualificaria o agente do crime para pena privativa de liberdade não superior a 04 anos ou, em se tratando dos Juizados Especiais Criminais, conforme reza a Lei 9.099/95, uma pena máxima não superior a 02 anos. 
Atendendo a estas exigências, observa-se que os ilícitos praticados pelas pesquisadas se caracterizam como de sem grave ameaça a terceiros, conforme preconiza as diretrizes da ONU, a Lei de Execução Penal e a Lei 9.099/95. Dentre os 36 delitos diversos ${ }^{13}$ pelos quais as mesmas foram condenadas, os de maior incidência são: furto $(19,8 \%)$, estelionato ${ }^{14}(8,6 \%)$, maus tratos $(7,4 \%)$, falsidade documental $(7,4 \%)$, uso de drogas $(6,2 \%)$, apropriação indébita $(3,7 \%)$, violação de direito autoral $(3,7 \%)$, lesão corporal $(3,7 \%)$ e peculato ${ }^{15}(2,5 \%)$.

Apesar da presença de $6,2 \%$ de condenações por uso de drogas, ilícito punível atualmente com pena de prestação à comunidade ou medida sócio-educativa pelo artigo 28 da Lei 11.343/06 (Lei de Drogas), todas as mulheres afirmam não serem usuárias ou já terem sido, mesmo que experimentalmente.

A partir de nossa experiência profissional durante os mais de 02 anos de existência da Central de Presidente Prudente, pode-se afirmar que a justificativa mais comum nestes casos é a de que teriam sido implicadas injustamente, pois a droga seria do namorado ou companheiro. Verdadeira ou não, esta justificativa tem fundamento real, já que não é rara a implicação de mulheres em crimes, e mesmo a prática direta deles, por força do envolvimento afetivo com o parceiro.

Quando à modalidade de sanção penal imposta, a pesquisa detectou que $57 \%$ cumprem prestação de serviço à comunidade, confirmando outros estudos que indicam ser esta a pena mais usual no Brasil. A segunda modalidade é a pena pecuniária, perfazendo $38 \%$, e, a terceira, a medida educativa de comparecimento a programa ou curso educativo, prevista no citado artigo 28 da Lei de Drogas.

Nas condenações com pena de prestação de serviço à comunidade, as mulheres, bem como aos homens, devem exercer tarefas gratuitas em entidades comunitárias ou

\footnotetext{
${ }^{13}$ A maioria deles apresentando a incidência de apenas 01 caso, correspondendo individualmente a $1,2 \%$ do total. Esclarece-se ainda que não foi possível detectar o ilícito em 08 casos, representando um percentual de 9,9\%, já que esta informação só passou a ser obrigatória nos relatórios da Central de Penas e Medidas Alternativas de Presidente Prudente a partir do ano de 2009.

${ }^{14} \mathrm{O}$ crime de estelionato está previsto no Código Penal no artigo 171 consistindo em "obter para si ou para outrem, vantagem ilícita, em prejuízo alheio, induzindo ou mantendo alguém em erro, mediante artifício, ardil, ou qualquer outro meio fraudulento".

${ }^{15}$ Pelo artigo 312 do Código Penal, peculato é "apropriar-se o funcionário público de dinheiro ou valor ou qualquer outro bem móvel, público ou particular, de que tem posse em razão do cargo, ou devia-lo, em proveito próprio ou alheio".
} 
públicas por um período que pode variar de 01 a 48 meses, normalmente em jornada de 08 horas semanais.

Quando se trata de medida educativa, o cômputo é feito pela freqüência a reuniões relativas aos programas ou cursos educativos. Assim, considerando que as condenações são, na maioria, por um período de 05 meses e que os encontros são habitualmente semanais, o cumprimento da medida exige a freqüência a cerca de 20 reuniões.

$\mathrm{O}$ atendimento dessa exigência, e das pertinentes à pena de prestação de serviço, não é tranqüilo para as mulheres atendidas pela Central de Presidente Prudente. Nossa experiência profissional permite afiançar que o maior obstáculo verbalizado pelas mulheres é o de não ter com quem deixar os filhos durante as horas em que estão cumprindo as condições decorrentes da sanção penal recebida.

Em nenhum atendimento realizado com os 409 homens atendidos pela Central de Presidente Prudente essa dificuldade foi verbalizada, indicando que a mesma não é vivenciada por eles.

Essa diferença de gênero fica mais nítida se levarmos em conta que $50 \%$ das mulheres possuem companheiro e que, se somarmos as divorciadas/separadas, que poderiam partilhar com o genitor dos filhos os cuidados com os mesmos, ter-se-ia $68 \%$ que, a priori, não deveriam enfrentá-la.

Assim, a menção a este tipo de dificuldade sugere que também no caso das cumpridoras de alternativas penais a responsabilidade pelos cuidados com os filhos recai sobre a mulher. Sugere ainda que também no caso delas o cumprimento de pena é perpassado por diferenças de gênero, em particular no que tange aos papéis familiares.

Segundo Saraceno (1997), os estudos sobre família mostram que ela vem passando por alterações significativas nas últimas décadas. Aponta, pois, para transformações na imagem tradicional de família como formada por pai, mãe e filhos; um modelo patriarcal que não corresponde mais à realidade, já que hoje os laços familiares são mais extensos e diferenciados.

Dados do IBGE (2009a) confirmam a existência deste processo de transformação na configuração da família brasileira. Dentre os aspectos a ele correspondentes, ressalta-se a redução do número de membros que passou de 4,3 pessoas em 1981 para 3,3 em 2001 e a do número médio de filhos que, em 2001, era 1,6 por família. Houve diminuição 
também no número de famílias formadas por casal com filhos (59,4\% em 1992 para $52,8 \%$ em 2002) e o aumento daquelas constituídas apenas por mulheres com filhos: 15,1\% em 1992 para 17,9\% em 2002.

Em paralelo com estas mudanças, cresceu também a proporção de mulheres como pessoa de referência da família, fenômeno evidente desde a década de 1980. Em 1981 o percentual de famílias chefiadas por mulheres era de 16,9\%, em 2001 era de 27,3\% e, em 2005 , de $30,6 \%$.

Nesta condição, a força de trabalho da mulher tende a ser a única opção para a sobrevivência do grupo familiar. Ela não é mais adicional, como no modelo tradicional, o que impõe à mulher o desafio de ser, ao mesmo tempo, cuidadora e provedora de suas famílias.

Com o cenário de crise mundial e as conseqüências da adoção de parâmetros neoliberais nas políticas sociais e econômicas, este desafio torna-se ainda maior. Tanto homens como mulheres tem sido atingidos pelo agravamento do desemprego estrutural e conjuntural, pelo achatamento salarial e pelo desmonte das políticas públicas sob influência desses parâmetros.

Porém, como nos aponta Irani (apud GOLDANI, 2002, p.31-32), as conseqüências são maiores para as mulheres:

\footnotetext{
Entre as mulheres brasileiras, que representam $40 \%$ das pessoas ocupadas em 1996, as condições tendem a piorar, posto que as tendências sejam de que se concentrem no setor informal da economia, passem para trabalhos eventuais e de tempo parcial. Também suas taxas de desemprego são bem maiores que para os homens, e o ramo que mais contribui para o emprego destas é o trabalho doméstico.
}

Realmente, as mulheres se mostram mais vulneráveis em termos de trabalho e renda. A título de exemplo, a partir de dados do IBGE (2009b) relativos ao ano de 2004, constata-se que, embora as mulheres empregadas apresentassem maior nível de instrução que os homens, elas estavam em grande desvantagem, verificável, dentre outros, pelo tipo de ocupação (17,1\% estavam ocupadas em trabalho doméstico que confere baixa remuneração); pela condição de carteira assinada ( $25,7 \%$ contra $33,7 \%$ dos trabalhadores homens); e pelos rendimentos médios mensais (as mulheres auferiam $69,5 \%$ dos rendimentos dos homens). 
Em vista disso, Nogueira (2004) avalia que a participação da mulher no mercado de trabalho é, simultaneamente, positiva e negativa. Positiva em razão da feminização do mundo do trabalho que, permitindo a emancipação feminina, minimizou as formas de dominação patriarcal no espaço doméstico. Negativa porque esta maior participação e emancipação ampliaram a exploração da mulher enquanto trabalhadora. Nas palavras de Nogueira (2004, s.p.), "ao mesmo tempo em que cria condições para a emancipação feminina, acentua a sua exploração ao estabelecer uma relação harmônica entre precarização e mulher".

Esta relação harmônica entre mulher e trabalho precarizado reforça, a nosso ver, a condição de vulnerabilidade social das mulheres e das famílias por elas chefiadas, nisso incluso o comprometimento, em maior ou menor grau, do papel socialmente atribuído a elas como cuidadoras dos filhos. Depara-se, portanto, com um círculo vicioso: para garantir a sobrevivência da família, mormente dos filhos, a mulher necessita inserir-se no mercado de trabalho; obtendo esta inserção, tende a não ter a quem delegar (ou dividir) os cuidados com os filhos; e, frente a isso, tende a enfrentar dificuldades adicionais para engajar-se no mercado de trabalho, colocando em risco a sobrevivência dos filhos e demais familiares.

Neste contexto, torna-se compreensível que a maior dificuldade apontada por elas em relação ao cumprimento da pena ou medida imposta seja a de não ter com quem deixar os filhos. Isto é, se para as mulheres em geral o desafio de conciliar necessidades pessoais com funções familiares e com as decorrentes do trabalho já é grande, para esse segmento da população feminina ele é ainda maior: a estas dimensões é acrescida a de cumpridora de pena ou medida alternativa.

\section{Considerações Finais}

Apesar de todos os avanços obtidos com a luta que as mulheres têm empreendido historicamente, ainda há muito a ser conquistado. Mesmo que os ganhos advindos do aumento de sua participação no mercado de trabalho devam ser valorizados, eles ainda não foram suficientes para igualá-la ao homem neste campo e para diminuir a dupla jornada e responsabilidade que esse aumento acarreta. Essa situação vem sendo acompanhada, cada vez mais, pela ausência de um companheiro com quem possa dividir 
as responsabilidades na esfera familiar ou socorrê-la nas dificuldades que vivencia pelo exercício de seus múltiplos papéis: mulher, mãe, profissional e chefe de família.

Frente a isso e ao desafio de exercerem simultaneamente o papel de cuidadoras e de provedoras da família, é fundamental a existência de políticas que permitam uma real proteção social a elas. Dito de outro modo, a difícil realidade em que a maioria das mulheres vive exige a existência de políticas sociais, na formulação das quais é imprescindível a observação da questão da desigualdade de gênero e as transformações pelas quais vem passando a família brasileira.

Os novos arranjos familiares demonstram que não existe um modelo pronto ou ideal de família. As relações familiares vão sendo estabelecidas conforme a situação, a necessidade e a realidade de cada um e essa diversidade têm que ser levada em conta na formulação e operacionalização de políticas públicas de atendimento às famílias, principalmente as chefiadas por mulheres. Exige, pois, um rompimento com o modelo que orientou (e em muitos casos ainda orienta) tais políticas: o de família tradicional formada por um casal heterossexual, casado legalmente e tendo o homem como provedor. A exigência é, portanto, de maior consideração à diversidade de arranjos familiares e igual rompimento com a visão de que aqueles que fogem a este padrão tradicional são "desestruturadas".

Se isso é verdadeiro para as mulheres em geral, para as privadas de liberdade ou em cumprimento de alternativas penais é ainda maior a exigência de políticas com este caráter e que permitam uma real proteção social, até porque, no caso delas, o volume de conquistas a serem obtidas é igualmente muito maior.

A caracterização efetivada neste texto evidenciou que, mesmo sendo minoria, elas enfrentam mais dificuldades que os homens no cumprimento das sanções penais. A construção cultural das relações familiares e da divisão de papéis masculinos e femininos perpassa também o mundo dos apenados ou sancionados e isto se manifesta inclusive na discriminação quanto às condições de cumprimento de pena (alternativa ou não) e na manutenção de diferenças de gênero relativas aos papéis familiares.

Com base nisso, pode-se dizer que, em um plano mais imediato, há a premência de políticas que, em face da ausência do companheiro ou do genitor dos filhos, permitam, ao 
menos, o atendimento das crianças que precisam de cuidados enquanto a mãe cumpre as condições decorrentes da sanção penal.

Em um plano mais mediato, porém, isso não basta. È imprescindível um maior debate sobre a situação das mulheres condenadas à privação de liberdade ou à alternativas penais, com especial consideração às especificidades que o cumprimento por parte delas encerra. È imprescindível também um maior envolvimento do poder público e da sociedade civil nesse debate para que, juntos, busquem medidas capazes de diminuir a disparidade entre homens e mulheres no tocante aos efeitos negativos adicionais que as sanções penais provocam.

Além disso, é imprescindível ainda que o direcionamento das políticas voltadas à mulher na condição de agente de crime não se afaste daquele que deveria ser assumido para outros segmentos da população feminina. Ou seja, que elas não reproduzam a realidade das políticas sociais brasileiras que faz "[...] com que a maioria das mulheres tenha direitos de proteção social não como cidadãs, mas apenas, por sua condição de esposa e/ou mãe" (GOLDANI, 2002, p. 34) e que, mais do que contribuir com ela no difícil desafio de conciliar seus múltiplos papéis, permita à mulher, cumpridoras ou não de sanção penal, galgar à real condição de cidadãs plenas de direitos.

\section{Referências}

BRASIL. Presidência da Republica. Decreto-Lei n. 2.848, de 7 de dezembro de 1940: Código Penal. Disponível em: < http://www.planalto.gov.br/ccivil/decreto-lei/del2848.htm>. Acesso em: 1 jun. 2008.

Lei n. 11.343, de 23 de agosto de 2006. Institui o Sistema Nacional de Políticas Públicas sobre Drogas - Sisnad; prescreve medidas para prevenção do uso indevido, atenção e reinserção social de usuários e dependentes de drogas; estabelece normas para repressão à produção não autorizada e ao tráfico ilícito de drogas; define crimes e dá outras providências. Disponível em: < http://www.planalto.gov.br/ccivil_03/_ato20042006/2006/lei/l11343.htm>. Acesso em: 12 ago. 2010.

Ministério da Justiça. Penas e medidas alternativas superam ainda mais o número de presos. 2009a. Disponível em: <http://www.mj.gov.br/data/Pages/MJ7CBDB5BEITEMID82ACB5AE83564767924682030 73F9834PTBRIE.htm>. Acesso em: 25 abr. 2009.

. Ministério da Justiça. Departamento penitenciário nacional. Dados consolidados 2007. Brasília. 2008. Disponível em: 
<http://www.mj.gov.br/depen/data/Pages/MJD574E9 CEITEMIDC37B2AE94

C6840068B1624D28407509CPTBRIE.htm>. Acesso em: 2 mai. 2009.

Secretaria nacional de justiça. Central Nacional de Apoio e Acompanhamento às

Penas e Medidas Alternativas. Manual de monitoramento das penas e medidas

alternativas. Brasília, 2002.

Departamento penitenciário nacional. Relatório estatístico analítico do sistema prisional do estado de São Paulo. Brasília, 2009b. Disponível em:

<http://www.mj.gov.br/data/Pages/MJD574E9CEITEMIDC37BZAE94C6840068B1624D284 07509CPTBRIE.htm>. Acesso em: 2 maio 2009.

BRASIL, Kátia. Estudo aponta que falta de aplicação de medidas alternativas deixa 59 mil na prisão. 07 jul 2008. FOLHAONLINE, São Paulo. Disponível em:

http://tools.folha.com.br/print?site=emcimadahora\&url=http\%3A\%aF\%2Fwww1.folha. Acesso em: 14 jul 2008.

CERNEKA, Heidi An. Mulheres Presas exigem seus direitos. 07 mar 2004. Pastoral

Carcerária. Disponível em: <www.carceraria.org.br/?system=news\&action=read\&id= 295\&eid=40>. Acesso em: 20 jul 2008.

DANIEL, Marcelo. Penitenciárias Femininas para Mulheres. Revista SAP. Edição Especial no 1. Novembro/2008. Disponível em http://www.sap.sp.gov.br/download_

files/pdf_files/revista/_2008.pdf. Acesso em 25 mai. 2009.

GOLDANI, Ana Maria. Família, Gênero e Políticas: famílias brasileiras nos anos 90 e seus desafios como fator de proteção. Revista Brasileira de Estudos de População, v.19, no1, p.29-48, jan./jun.2002.

IBGE. Instituto Brasileiro de Geografia e Estatística(a). IBGE detecta mudanças na família brasileira. Disponível em http://www.ibge.gov.br/home/presidencia/noticias/noticia_ visualiza.php?id_noticia=774\&id_pagina=1 Acesso em 30 mai 2009.

IBGE. Instituto Brasileiro de Geografia e Estatística(b). A Família Brasileira. Disponível em http://www.ibge.gov.br/ibgeteen/pesquisas/familia.html\#anc1 Acesso em 30 mai 2009

NOGUEIRA, Claudia Mazzei. A Feminização do Mundo do Trabalho: entre a emancipação e a precarização. São Paulo: Autores Associados, 2004.

PARANÁ. Ministério Público do Estado do Paraná. Manual de Procedimentos para Cumprimento de Penas e Medidas Alternativas nas Instituições Conveniadas. Curitiba. 2008.

SARACENO, Chiara. Sociologia da Família. Lisboa: Estampa, 1997.

SARACENO, Chiara. A dependência construída e a interdependência negada. Estruturas de gênero e cidadania. In: BORRACLEI, G e GROPPI, A. (Org.). O Dilema da Cidadania. São Paulo: UNESP, 1995. p.205-234 
SÃO PAULO. Manual Central de Penas e Medidas Alternativas do Estado de São Paulo. Secretaria da Administração Penitenciária. Departamento de Reintegração Social Penitenciário. São Paulo: 2007.

SÃO PAULO, Secretaria da Administração Penitenciária. Censo Penitenciário-Perfil do Preso. 06 mar. 2003. Disponível em: <http://www.sap.sp.gov.br/common/ vinculado.html>. Acesso em: 28 jun. 2008.

SÃO PAULO, Secretaria da Administração Penitenciária. Unidades Prisionais. Disponível em: <http://www.sap.sp.gov.br/>. Acesso em: 02 mai. 2009.

SUCUPIRA, Fernanda. Mais da metade das mulheres presas estão em cadeias provisórias. Fórum das Entidades Nacionais de Direitos Humanos. 23 jun. 2006. Disponível em: $<$ http://www.direitos.org.br/index.php?option=com_content\&task= view\&id=1486\&ltem>. Acesso em: 28 jun. 2008. 